Sección uno: Ensayo

Educación y Exclusión social

\title{
Educación y exclusión digital: los falsos nativos digitales ${ }^{1}$
}

Education and digital exclusion: false digital natives

\author{
Manuel Granado Palma \\ Universidad de Cádiz \\ manuel.granado@uca.es
}

\section{Resumen}

El proceso de digitalización se ha globalizado socialmente. Las tecnologías de la información y comunicación (TIC), también con el componente relacional (TRIC) y, fundamentalmente, las de aprendizaje y conocimiento (TAC), forman parte de la cotidianidad y comienzan a ser imprescindibles. Las personas nacidas a partir de los ochenta son inherentes a ellas y al uso natural de los dispositivos digitales, adjudicándoseles el apelativo de "nativas digitales". Se las considera "digitalizadas", salvo por causas de accesibilidad derivadas por la variable económica. Han nacido con la digitalización, pero no ha habido una conciencia social para su formación y educación en un uso racional, crítico y reflexivo. La variable educativa determina una "brecha digital" entre quienes la reciben y quienes no, aunque con una manifestación implícita, no tan visible como la provocada por la accesibilidad, pero que genera no sólo la exclusión de las "falsas nativas digitales", sino que unas van a tener el potencial proactivo, de dominio y manipulación, frente a otras pasivas, manipulables y sin capacidad crítica reactiva.

Palabras clave: Educación, TIC, TRIC, TAC, digitalización, exclusión, nativo/inmigrante digital, brecha digital.

\begin{abstract}
The digitization process has been globalized socially. Information and communication technologies (ICT), also with the relational component (TRIC) and, fundamentally, those of learning and knowledge (TAC), are part of daily life and they begin to become essential. The generations born from the eighties are inherent to them and to the natural use of digital
\end{abstract}

${ }^{1}$ Recibido: 29/05/2018 Evaluado: 04/07/2018 Aceptado: 25/07/2018 
devices, being awarded the nickname of "digital natives". They are considered "digitized", except for reasons of accessibility, derived by the economic variable.. They have been born with digitalization, but there has not been a social awareness for their training and education in a rational, critical and reflective use. The educational variable determines a "digital divide" between those who receive it and those who do not, although with an implicit manifestation, not as visible as that caused by accessibility, but that generates not only the exclusion of "false digital natives", but some will have the proactive, domain and manipulation potential, against other passive, manipulated and without reactive critical capacity.

Keywords: Education, ICT, ICRT, LKT, digitalitation, exclusion, native/inmigrant digital, digital divide.

\section{Hacia la desmitificación del concepto de persona "nativa digital"}

El concepto de "nativa digital" surge a partir de un ecléctico artículo de Marc Prensky (2001), conferenciante norteamericano, publicado en la revista "On the Horizon", en contraposición al concepto de "inmigrante digital". El impacto de la digitalización conllevaba una significativa ruptura generacional entre aquellas personas nacidas desde mediados de la década de los ochenta (nativas digitales), inmersas en la era digital desde su nacimiento y que no han tenido que desarrollar ningún proceso de adaptación a la misma; y las generaciones precedentes (inmigrantes digitales), nacidas en la era analógica y que recibían la digitalización como algo ajeno a ellas. Para Prensky las nativas digitales son personas que reciben la información rápidamente, que les gusta el trabajo en paralelo y la multitarea, que prefieren imágenes a textos, que prefieren el acceso aleatorio, que funcionan mejor cuando trabajan en red, que prosperan con la satisfacción inmediata y bajo recompensas frecuentes y que prefieren los juegos al "trabajo serio". Habla de una "discontinuidad", estableciendo que las generaciones nativas digitales piensan y procesan la información de manera diferente a las generaciones anteriores, llegando a producirse un cambio en los patrones de pensamiento. Las generaciones nativas digitales se manejan con absoluta naturalidad antes los continuos avatares tecnológico-digitales, procesándolos con inmediatez y respondiendo con los conocimientos y habilidades exigidos para su máximo aprovechamiento.

Las generaciones nacidas desde mediados de los ochenta, "Millenials" o "Generación Y", y las posteriores, nacidas desde mediados de los noventa, "Generación Z" (Atrevia, 2017) han tenido a su disposición, prácticamente desde su nacimiento, toda la gama de dispositivos digitales, gadgets informáticos y una variedad de multipantallas, ya sean como entretenimiento, como información, como comunicación o como relación (relaciones virtuales). Desde smartphones a smartwatch, pasando por tablets, portátiles, PC, infinidad de aplicaciones digitales o la clásica televisión, aunque a través de plataformas digitales y con un sentido diferente, formando parte de la sinergia entre pantallas, la televisión conectada, el multitasking y la televisión social. Yendo un poco más allá, las generaciones nativas digitales se definen culturalmente por las diferentes maneras de interacción con la información, la comunicación y relaciones con los demás, ya sean con individuos o con colectivos (Freire, 2007). Pero la población nativa digital viene marcada por la heterogeneidad, pues existen variables que hacen que sus procesamientos sean muy 
diferentes. Prácticamente todas conocen y utilizan la tecnología con desenvoltura, pero no todas están preparadas para ser sujetos activos de las mismas, de explorar y de crear, aunque ráramente serán conscientes de ello, y si lo son, estarán convencidas de superar esas "limitaciones" fácilmente.

En la globalización digital, el uso de las multipantallas se ha estandarizado. El manejo de toda esta tecnología apenas tiene secretos para estas generaciones. Aludiendo a Prensky, pareciese que ya nacen con unas potencialidades psicomotrices y una coordinación óculomanual superior a las generaciones anteriores. Todo es fácil para ellas por ser recibidas con naturalidad. Nada es extraño. Consecuencia de ello es también un cambio en su actitud ante las pantallas, pasando, en teoría, de ser sujetos pasivos receptores de un mensaje (espectadores) a sujetos más activos y participativos, que generan y son fuente activa de información y comunicación, con capacidad decisoria sobre lo que ven y sobre cómo lo ven. Por otro lado, las multipantallas no obligan a elegir entre ellas, ni siquiera en alternancia, sino que están asociadas para poder interactuar con ellas de manera simultánea en un sistema de aprendizaje ubicuo (Quicios, 2015). Y todo ello con el factor de intercomunicación social, ya sea en redes sociales con personas conocidas o no conocidas. Es una forma de comportarse, de estar en el mundo y, sobre todo, de comunicarse; también de estar en el sistema de comunicación mediatizada (Callejo, 2010). Las diferencias afectan tanto a la significación como a la intensidad en el uso de las herramientas digitales.

Atendiendo a un estudio de Imedia Connetion (2013) se pueden definir cuatro tipos de usuarios multipantallas:

- Content Grazers: consumidores simultáneos de diferentes pantallas. Mucho contenido, pero sin profundizar en ninguno de ellos.

- Investigate Spider Webers: consumidores de una pantalla principal y de otras pantallas secundarias para información adicional sobre el contenido de la principal.

- Social Spider Webers: consumidores de multipantallas como socializadoras del contenido, esto es, compartiendo con otros usuarios.

- Quantums: consumidores simultáneos de multipantallas con usos específicos de cada una de ellas

Este potencial digital contrasta con las generaciones anteriores, de cultura analógica, que reciben la digitalización como algo nuevo, ajeno a su cotidianidad, tanto social, como laboral, como de ocio, etc. Una parte de esta población se queda en su mundo analógico, pero otra parte es consciente de la dominante digitalización y su imparable expansión y se ve obligada a iniciarse en un arduo proceso de reconversión de lo analógico a lo digital para la integración de los dispositivos digitales en su realidad y poder mantenerse integrado social y laboralmente. La reinserción al mundo digital se centra en su uso desde una perspectiva funcional, frente al uso fundamentalmente relacional de las generaciones nativas digitales. Esta parte de la población más veterana es la que conforma lo que Prensky viene a llamar "inmigrantes digitales".

Se presenta así una sociedad dividida en dos sectores cognitivos y una barrera estructural entre la oferta educativa tradicional (analógica) y las características actitudinales de las nuevas generaciones, que se desarrollan evolutivamente con parámetros muy distintos a los 
establecidos por las generaciones anteriores. El imparable proceso de digitalización (revolución digital) irá determinando que ese choque generacional se termine decantando a favor de las poblaciones de personas nativas digitales.

Pero la dualidad conceptual no se puede llevar a la constatación de la realidad de forma tan determinante ni absoluta. Ciertamente existe una revolución digital y un paso de lo analógico a lo digital, pero no son dos realidades en oposición, ni se puede establecer como una única estructura clasificatoria. En todo proceso mental y evolutivo hacia lo digital subyace un fondo analógico al que no se debe renunciar (Gértrudix, 2010). Se están desarrollando nuevas competencias, pero eso no implica necesariamente tener que dejar de desarrollar o "desaprender" las ya adquiridas, sino que la inmigrante digital debe digitalizarse a partir de sus conocimientos y habilidades analógicas y, en todo caso, su adecuación a la digitalización; y a la inversa, la nativa digital requiere compatibilizar su natural potencial de digitalización con conocimientos, destrezas y habilidades propias de la cultura analógica, pero que deben resultar determinantes para una perfecta acomodación y uso de lo digital.

El artículo de Prensky alcanzó una gran dimensión en muchos campos de conocimientos, tanto mediáticos, como académicos, universalizándose los conceptos "nativa/inmigrante digital" como referentes de la población digital y la población analógica. Sin embargo, es un artículo vacío de fundamentación científica y empírica, pues los datos aportados carecen de referenciación, al igual que muchas de sus afirmaciones, llegando incluso a conclusiones tan grandilocuentes como las que invocan a un "determinismo biológico". Estudios como los de Clotfelter (2008) o Kennedy (2008) ya advertían del simplismo de la catalogación de Prensky y de la complejidad y las grandes diferencias internas de las generaciones nativas digitales por diferentes cuestiones, sobre todo económicas. En España también son muchas las voces que cuestionan el paradigma de Prensky, como Daniel Cassany (2008), Jordi Busquet (2010), Dolores Reig (2013), Robert Martínez (2010) o más reciente y explícitamente en la obra coordinada por Susana Lluna y Javier Pedreira (2017), con un título por sí elocuente: "Los nativos digitales no existen", en cuyo prólogo dice Enrique Dans en referencia a las personas nativas digitales: “(...) al descender en el rango de edad, parecían ser no sólo más ignorantes, sino más escépticos, más reactivos, más descreídos respecto a los posibles beneficios que la tecnología podía reportar. No era sólo que no supieran... es que tampoco parecían querer saber". La complejidad y diferencias intrínsecas entre la población nativa digital es más alarmante cuanto mayores son las diferencias socioeconómicas de la sociedad donde se manifiestan.

El ensayo de Prensky es válido como artículo de opinión y divulgación, pero al margen de su falta de rigor científico, parte de unas premisas reduccionistas y excluyentes en sí mismas, concibiendo las generaciones nativas digitales como un todo uniforme, sin otras consideraciones como las educativas, las culturales, las geográficas, las familiares o las económicas. Asumiendo sus parámetros se corre el riesgo de trivializar y asumir una actitud demasiado ingenua sobre sus prelados, pudiéndose concluir en la banalización de una situación de gran complejidad. El mayor detractor del binomio nativa/inmigrante digital será años después el propio Prensky (2010), que renegará de su diferenciación para considerar el más apropiado concepto de "sabiduría digital", algo no relacionado ni con la edad ni con el status económico, sino como algo actitudinal que entronca con el factor educacional. 


\section{Desigualdades y exclusión, pese a la globalización digital}

El concepto de "brecha digital" (Hoffman, 2001), fue acuñado como "Digital Divide" a finales de los noventa en EEUU en unos informes presidenciales sobre la problemática de las desigualdades entre "conectados/desconectados" por diferentes motivos (Fernández del Moral, 2012). Es sinónimo de exclusión y marginación respecto al dominio de las TRIC y TAC y, por ende, de la plena integración en una sociedad cada vez más digitalizada. Las brechas digitales son motivos de exclusión de la sociedad del conocimiento, y de configuración de una marginación social y personal (Cabero, 2004).

Una variable muy estudiada como valor determinate de la brecha digital es la cuestión económica (inforicos/infopobres). Ciertamente la variable económica ha sido una de las principales potenciadoras de una posible situación de marginalidad y exclusión social de las personas menos favorecidas en este sentido (Pinto Arboleda, 2014). No obstante, la gradual universalización de las TRIC prácticamente en todos los sectores sociales y la progresiva incorporación de ellas en la escuela, hacen que esa dualidad se vaya reduciendo hasta dejarla en efectos cada vez menos relevantes (Ferreiro, 2005). En cualquier caso, la natural introducción de las tecnologías digitales al ámbito educativo, sobre todo en metodologías constructivistas, no debe quedarse en la virtualidad, sino que debe desarrollarse en simbiosis con las experiencias de contacto con el mundo real.

Aunque en este artículo se pone relevancia en las variables educatico-formativas como determinates de la brecha digital, es preciso aclarar que no se trata de una cuestión causa efecto, sino que es resultante de confluencias de variables, considerándola como un "elemento multidimensional" (Cabero, 2004), con múltiples factores que surgen de los análisis comparativos económicos, geográficos, culturales, etc. (Rosabal, 2003), como las barreras de localización, geográficas, de sexo, de idioma, socioculturales, religiosas, o las propias de la heterogeneidad de cada persona y la diversidad funcional. Se trata de dimensionar el potencial de cada una de ellas, restando valor a la variable generacional y económica y fortaleciendo la variable formativo - educativa.

Según un estudio del Ministerio de Educación, Cultura y Deporte (2017) sobre el uso de las TIC en los centros educativos españoles en el curso 2015/16, se ha pasado de una media de 4,3 alumnos/as por ordenador en el curso 2009/10 a 3 alumnos/as por ordenador en el curso 2014/15. Otro dato significativo de este estudio es el acceso a internet de los centros educativos, pasando de tenerlo el $49,8 \%$ en $2009 / 10$ a tenerlo el $82,9 \%$ en $2014 / 15$. Respecto al uso de internet por el alumnado en los centros educativos, se pasa del 59,3\% al 67,7\%, siendo mayor el uso en el hogar, en donde se pasa del 75,7\% al 89,2 \%. Por otro lado, es una obviedad que a medida que pasan los años, por razones naturales, las generaciones nativas digitales van creciendo en número en detrimento de las de inmigrantes digitales. Las tecnologías de información, relación y comunicación, así como las de aprendizaje y conocimientos son cada vez más un recurso en sí mismas y han sido potenciadoras de un contexto de contrastes entre quienes acceden a ellas y quienes no, generando oportunidades y desigualdades (Robles, 2007). Según datos del INE (2016), el 81,9\% de los hogares españoles tienen acceso a Internet; y el $96 \%$ de adolescentes tienen smartphone, un dispositivo digital de gran potencial, pero cuyo uso se centra básicamente para fotos y mensajería instantánea. 
Cada vez va teniendo menos sentido la consideración de choque generacional entre profesorado/analógico y alumnado/digital, pues una buena parte del profesorado comienza ya a ser también de generaciones nativas digitales. Y ello a pesar de que el ritmo de nuevas contrataciones se ha visto mermado por la crisis económica y por los recortes en materia de educación, lo que ha derivado en un envejecimiento del profesorado, como señala un estudio comparativo de CCOO (2014). Según el estudio anteriormente citado del Ministerio de Educación, Cultura y Deporte, el porcentaje global de profesores/as menores de 30 años era del 7,1\% en el curso 2015/16, siendo del 29\% la franja de edad de entre 30 a 39 años, del $30 \%$ la de entre 40 a 49 años, del 28,6\% la de entre 50 a 59 años y del 5,2\% la de mayores de 60 años.

La progresiva superación de desigualdades generacionales y económicas para el acceso a las herramientas digitales podría derivar en una conciencia de globalización digital y con ello una relajación respecto a la brecha digital y las posibilidades de exclusión y marginación de la parte de población más desfavorecida. Para esa accesibilidad, las variables económicas o generacionales siguen siendo de manifestación notoria y explícita, fácil de detectar y determinar sus características, sus orígenes, sus consecuencias y sus posibilidades de resolución; $\mathrm{y}$, además, previsibles. Basta un simple ejercicio deductivo para inferir situaciones y contextos susceptibles de sufrirlas. No desaparecen dentro del extenso campo de multivariables, pero perdiendo relevancia. Sería tan fácil como errático pensar que las generaciones nativas digitales son per se expertas digitalmente, que nacen enseñadas, pues sus conocimientos suelen ser superficiales, pudiendo tener un gran dominio del manejo tactil, pero carentes de racionalización (Busquets, 2012). Si bien es cierto que la digitalización se va globalizando y extendiendo su acceso y utilización, sería un error considerar la global capacitación para su uso racional. Actualmente surge una nueva situación que trasciende el problema a la máxima dimensión: la variable educativa.

\section{Nativos digitales no digitalizados: el falso nativo digital}

La simplificación de conceptos y considerar como automáticamente digitalizados a las generaciones nativas digitales conlleva a una problemática ulterior que deriva en la no conisderación de desigualdad digital entre la población de estas generaciones. Determinar con un nombre a una realidad social con tantos distintivos globales y estandarizados resulta, cuanto menos, impreciso, sobre todo si se aspira a que dichas generaciones cumplan todas las características que la definen conceptualmente y que todas las personas nacidas en esas generaciones tengan las mismas competencias de uso. Autores como John Palfrey y Urs Gasser (2008), codirectores del Grupo de Investigación Internacional Digital Natives, cuestionan que todas las personas de las generaciones nativas digitales pueden considerarse como tales. Siguiendo con la dualidad conceptual brenskyniana, nos adentramos en la diversidad de capacitación digital entre personas de generaciones nativas digitales, encontrando individuos de estas generaciones que pueden considerarse como "analfabetos digitales", pese a haber nacido y haberse desarrollado inmersos en el universo digital. El físico y matemático sueco Marcelo Milrad (2013) va más allá al hablar de "ignorantes analógicos", considerando que, aunque esta generación tiene un dominio natural tecnológico de las herramientas digitales, parte de esta población carece de algunas facultades necesarias para su correcto uso, como disciplina, rigor intelectual y capacidad de análisis. Bajo una apariencia de dominio absoluto de los dispositivos digitales, pues han nacido con ellos, 
subyacen graves carencias racionales de uso, con la gravedad de ser implícitas, de pasar desapercibidas.

Es un error considerar que por haber nacido antes o después de una determinada fecha ya se tienen unos condicionantes quasi genéticos pro facilitadores para la digitalización, tanto como de lo contrario. De hecho hay personas nativas digitales que presentan graves carencias respecto al uso de las TRIC y las TAC, mientras a la inversa, personas inmigrantes digitales pueden haber desarrollado una alta capacitación digital. Podría hablarse en referencia a los primeros como "nativos digitales no digitalizados" o "falsos nativos digitales", abriéndose la consideración de brecha digital como manifestación explícita de desigualdades respecto al acceso y uso de las herramientas digitales (Alva, 2015). Ser de la generación nativa digital no faculta para ser competente digital.

Respecto a esta brecha digital y sus consecuencias de exclusión habría que atender a múltiples variables, si bien los primeros estudios respecto a ella se centraban casi exclusivamente en cuestiones socioeconómicas, especialmente en análisis de tipo comparativo entre países. La variable socioeconómica sigue siendo determinante en sociedades menos desarrolladas tecnológicamente y con grandes diferencias económicas entre la población o en estudios internacionales, pero en las sociedades más desarrolladas tecnológicamente, como sería el caso de la española, el factor económico comienza a perder peso como determinante de la brecha digital, que no por ello desaparece, sino que adquiere otra dimensión, pero que hay que enlazar más con actitudes culturales y educativas que con el acceso a la tecnología (Fryer, 2006). Esa brecha digital de origen cultural y educativo se manifiesta de forma implicita, mucho más sutil que las derivadas por factores geográficos o socioeconómicos. El hecho de la global accesibilidad hace pensar en una igualdad de uso y, por tanto, una ausencia de exclusión. Nada más lejos de la realidad. Ciertamente la exclusión no sólo existe, sino que puede alcanzar límtes de extrema gravedad. Algunos autores, como Javier Tarango (2009) la definen como "brecha cognitiva" o "brecha intelectual", entendida como una nueva dimensión de brecha digital surgida del desarrollo cognitivo imprescindible para desempeñarse activamente en la era digital. Habría que considerarla no tanto respecto al acceso o no acceso a las herramientas digitales, sino respecto al uso que se hace de ellas.

Las generaciones nativas digitales presentan una acomodación tecnológica natural en la operatividad con herramientas digitales, en su manipulación y tratamiento. Viven en un continuo estado de intercomunicación, reciben una gran cantidad de información, están en contacto con multitud de emisores de información y comunicación, acceden a infinidad de plataformas sociales y comerciales, interactúan a través de las diferentes redes sociales para variados fines, informativos, sociales, comerciales, divulgativos, lúdicos, etc. Lo que hay que cuestionarse es la capacidad de procesamiento y uso de todo ese potencial comunicativo e informativo, la capacidad reflexiva, la capacidad de discriminación, de selección y de elección, la capacidad en la toma de decisiones, la capacidad de autonomía e independencia, y, sobre todo, la capacidad crítica. Todas estas capacidades no vienen determinadas por la fecha de nacimiento, sino que sólo pueden desarrollarse a través de la formación y la educación. Y la mayor o menor formación en estos aspectos es lo que va a hacer que una parte de esas generaciones nativas digitales puedan utilizar las TRIC y TAC aprovechando todo su potencial, desarrollándose como sujetos proactivos, emisores, creadores y en constante evolución; mientras otra parte de esa población termina siendo víctima de la 
digitalización, cayendo en las redes de la desinformación, la manipulación y el adoctrinamiento, desarrollándose como sujetos pasivos sin capacidad crítica ni de reacción. A la inversa, una parte de las consideradas generaciones inmigrantes digitales (analógicos) se incoorporan con una gran preparación y formación en el uso y aprovechamiento de las herramientas digitales, de manera que su acercamiento al mundo digital se convierte más que en un movimiento migratorio, en un movimiento de colonización. Es más relevante el debate educativo que el generacional. No es una cuestión de edad, sino de formación y educación.

Por otro lado, es un debate de carácter temporal, pues en cuestión de unas décadas dejará de tener vigencia, ya que las actuales jóvenes generaciones nativas digitales coparán la totalidad de la población y las generaciones inmigrantes digitales, de formación analógica, habrán dejado de existir. Se acabará la dualidad nativo/inmigrante digital, pero al ritmo de avance tecnológico que llevamos será una cuestión sucesoria, y con toda probabilidad las digitalizadas generaciones actuales pasarán a una situación de desfase frente a las futuras generaciones. A los milllennials no les quedará otra que reciclarse para adaptarse a las futuras revoluciones tecnológicas por venir y no quedar anquilosados en la digitalización (Ferrer, 2010).

\section{Educación y formación, variables determinantes de la "brecha digital"}

La educación no es una variable nueva surgida de la era digital, es más, es lo mismo de siempre. La misma problemática surgida de la incorporación social de las nuevas tecnologías, de los mass media, de la prensa, de la publicidad, de la televisión, del cine, de la radio, etc. El nivel formativo y educativo determina una dualidad, una ruptura, una desigualdad, una brecha entre aquellas personas que han recibido una educación en la utilización de las herramientas, sean cuales sean, y aquellas otras que las utilizan sin más. En el campo digital las repercusiones sociales de esta dualidad son de extrema gravedad y puede derivar en que aquellas personas que carecen de dicha formación y educación no sólo sufran la exclusión, sino que queden a expensas de la manipulación y el engaño de la parte más pretenciosa y pérfida de quienes las dominan. Se podría hablar de "dominio/sumisión digital" y considerar que no viene determinada, al menos directamente, por la variable económica o generacional, sino fundamentalmente por la variable cultural formativo-educativa. Y no de forma aislada, sino considerando las correlaciones con otras variables.

La formación y educación es una necesidad para el uso adecuado de los medios de comunicación de masas. El potencial de manipulación y subjetividad de las tecnologías digitales, sujeta a intereses políticos, económicos, culturales, comerciales, ideológicos, religiosos, personales, etc., hace necesaria la concienciación para el desarrollo de una educación crítica y reflexiva ante ellas. Es una realidad desde la propia lectura, tanto de la prensa escrita, como de obras literarias. No se trata sólo de saber deletrear, ni tan siquiera de comprender el mensaje, que serían las exigencias mínimas de uso, sino que habría que hacer una lectura más profunda e inteligente, pudiendo ir más allá de lo expresamente escrito, alcanzando el posible mensaje oculto, tácito, las intenciones del emisor; pudiendo disfrutar de la forma lírica, de la belleza de la combinación de palabras; desarrollando una lectura analítica que permita ejercer autonomía de opinión, ya sea favorable, contraria o indiferente, propiciando una opinión personal al respecto; y posibilitando la acción y creación desde la propia subjetividad. Hacer, en definitiva, un uso racional de un medio de comunicación como 
es el lenguaje escrito. Esa facultad no es innata, ni tiene relación directa de causa efecto con variables económicas o generacionales, sino que va ligada a la formación y educación, sin obviar que efectivamente detrás de la variable educativa subyacen cuestiones socioculturales y económicas. La educación y formación digital, aunque tiene un transfonso socioeconómico (Ávila, 2016), no necesariamente debe ir asociado al nivel académico. De hecho, en el alumnado universitario es notoria la explícita manifestación de carencias de un uso racional, reflexivo y crítico de los recursos digitales y la información recogida de ellos (Granado, 2011).

Además de las posibilidades manipulativas, otra dimensión de la digitalización es la saturación de información, de manera que resulta imposible atender a todas, lo que obliga a discriminar, seleccionar y elegir. Se produce lo que Pérez Tornero (2012) define como "embotellamiento perceptivo". Y en este proceso también resulta esencial la educación y formación para el correcto análisis. Disponer de información no produce de forma automática conocimiento. Puede resultar paradójico, pero no por tener más canales de información se tiene mayor conocimiento (Area, 2005), pues es necesario el procesamiento mental adecuado para convertir esa información en conocimiento. Transformar la información en conocimiento exige destrezas de razonamiento para procesarla, organizarla, interrelacionarla, analizarla, sintetizarla y hacer inferencias y deducciones de distinto nivel de complejidad; en definitiva, comprenderla e integrarla en los esquemas previos de conocimiento.

\section{Educación y formación digital}

Más allá de alarmismo sobre los paradigmas y fines de la educación, la digitalización debe considerarse como un vasto campo de posibilidades educativas, posibilitando la apertura de la escuela a la sociedad, ampliando las interacciones con el entorno y acercando el objeto de estudio. Los dispositivos digitales son recursos constructivistas que deben intervenir en el proceso de enseñanza-aprendizaje. Herramientas (aplicaciones) como redes sociales, wikis, blogs, chats, etc. facilitan la inmaterialidad, la interacción, la instantaneidad, la edición y manipulación, la difusión, etc., con lo que se capacita para crear, compartir y dominar el conocimiento. Pero no sólo deben servir como recursos, como herramientas para el trabajo de otras disciplinas (educar $\mathrm{CON}$ ), sino que también deberían considerarse como aprendizaje en sí mismas (educar EN), con la finalidad de desarrollar las destrezas técnicas y la capacidad analítica, crítica y reflexiva para su correcto tratamiento (De Pablos, 1997). Lo que no debe producirse en ningún caso es la anulación de las experiencias reales con el entorno y las interrelaciones personales. La educación del siglo XXI exige un sistema adaptado a las demandas de una nueva realidad que evoluciona constantemente y que promueve la diversidad, las necesidades y las motivaciones propias del alumnado (Martín Labora, 2005). Porter-Moix denunciaba, hace ya más de treinta años, la necesidad urgente por preparar y capacitar a la sociedad para que sus funciones receptoras se realizasen en las mejores condiciones de aprovechamiento desde un punto de vista crítico, capaz de sacar el máximo provecho de la saturación informativa.

El debate sobre la formación en el uso de las herramientas digitales, más allá de las cuestiones de uso tecnológico y su utilización como recurso mediático para el tratamiento de los contenidos curriculares (educar $\mathrm{CON}$ ), debe centrarse en la educación sobre ese uso para poder utilizar esas herramientas de forma racional y crítica (educar EN). Esto debe venir 
avalado y respaldado desde una perspectiva social, pero también política e institucional, que realmente garantice de forma seria su implementación teórica, experimental y económica. En ese contexto es necesario fijar indicadores sobre los usos e impactos de las TRIC y TAC en el ámbito educativo y en la complejidad de definir competencias digitales en sí mismas y como herramientas para otras competencias curriculares.

El objetivo final no debe ser otro que ofrecer los mecanismos necesarios para discriminar y seleccionar la información y procesarla de manera racional, reflexiva y crítica, posibilitando una actitud proactiva y creativa, con el potencial de cambiar y mejorar la sociedad, y no tanto de convertirse en un nuevo eslabón en la cadena de aborregamiento de pensamiento alienado. $\mathrm{El}$ analfabetismo digital puede conllevar riesgos que atenta contra la propia intimidad y vida privada, siendo vulnerables a situaciones que atentan contra los derechos más personales y expuestos a riesgos muy dañinos como la adicción, el acoso, el delito cibernético, etc. Ante sujetos analfabetos digitales, completamente pasivos ante la información y comunicación derivada de los medios y de otras personas (influencers), tanto analógicos como especialmente digitales, hay quienes encuentran un vasto campo de fieles sometidos a los intereses de su imperio y que resultan fácilmente manipulables. Yuhyun Park (2016), presidenta de InfollutionZERO Foundation, alerta en un artículo en Word Economic Forum sobre los peligros del analfabetismo digital, agravado por su manifestación implícita y la prácticamente nula sensibilización social y educativa. El centro de preocupaciones no debe estar tanto en las destrezas tecnológicas, como en desarrollar un uso racional, con capacidad de protegerse de los riesgos cibernéticos, la utilización responsable y crítica de los dispositivos digitales, evitar normas de conducta tóxica que afecten a la capacidad para interactuar con los demás y reforzar la capacidad y confianza para superarse en línea. Se identifican ocho capacidades que son necesarias desarrollar para hacer un uso racional e inteligente de la digitalización: capacidad de crear y administrar una identidad integral saludable; capacidad de administración temporal y autocontrol; capacidad para detectar situaciones malintencionadas; capacidad de autoprotección; capacidad de discreción; capacidad de discriminación selectiva de la información y comunicación; capacidad de comprensión y prevención de consecuencias; y empatía digital.

Para superar esta barrera sería necesario un proceso educativo centrado en "educar EN", con unos ejes metodológicos centrados en el constructivismo, la retroalimentación, la significabilidad, la bidireccionalidad comunicativa, incentivando la actitud crítica, la imaginación y la creatividad. Una sociedad educada y formada desde la responsabilidad crítica y amparada por gobiernos e industrias sensibilizadas por esta realidad, servirá como soporte de una cultura digital libre y de confianza. Tanto desde el ámbito educativo, como familiar, como social en general, es necesario tomar conciencia de la brecha social que se está generando, con repercusiones mucho más graves que las que podía presumirse respecto a variables económicas o generacionales. La sociedad comienza a dividirse entre los que dominan el uso de la digitalización y quienes sólo las utilizan tecnológicamente, dando lugar a una parte potencialmente activa, dominante, manipuladora y poderosa y otra parte potencialmente pasiva, vulnerable, manipulable y débil. ¿Hay mayor exclusión? Y, sin embargo, esa exclusión se manifiesta oculta, camuflada, implícita, agravándose sin que se tomen las medidas político-educativas necesarias para evitarlas. ¿O es que no interesa? 


\section{Referencias}

Alva de la Selva, A. R. (2015). Los nuevos rostros de la desigualdad en el siglo XXI: la brecha digital. Revista mexicana de ciencias políticas y sociales, 60(223), 265-285.

Area, M. (2005). La educación en el laberinto tecnológico. De la escritura a las máquinas digitales. Barcelona. Editorial Octaedro-EUB.

Asociación Latinoamericana de Integración (ALADI) (2003). La brecha digital y sus repercusiones. Recuperado de https://bit.ly/2uMgDnY (3/5/2018).

ATREVIA (2017). Generación Z. II Fase. El dilema. Consultoría Global de Comunicación de espíritu latino. Deusto Business Scholl. Universidad de Deusto.

Ávila, P. (2016). Construcción de ciudadanía digital: un reto para la Educación. Suplemento Signos EAD.

Bernardo Paniagua, J.M. (2006). El sistema de la comunicación mediática. Valencia: Tirant lo Blanch.

Busquets, J. y Uribe, A. C. (2012). (2012). El uso de las TIC y la brecha digital entre adultos $y$ adolescentes. Primer esbozo del estado de la cuesfión. Grupo Proyecto AUSTICA. Recuperado de https://bit.ly/2x1ISBq (13/04/2018).

Busquet, J. y otros. El uso de las TIC y la brecha digital entre adultos y adolescentes. II Congreso Internacional Asociación española Investigación de la Comunicación. Málaga, 2010. Recuperado de https://bit.ly/2O84Lp9 (16/4/2018).

Cabero, J. (2004). Reflexiones sobre la brecha digital y la educación. En Soto, F.J. y Rodríguez, J.(coords.): Tecnología, educación y diversidad: retos y realidades de la inclusión social. Murcia, Consejería de Educacióny Cultura, 23-42.

Cabero, J., Córdoba, M. (2009). Inclusión educativa: inclusión digital. Revista de Educación Inclusiva. Vol. 2, n 1, págs. 61-77. Recuperado de https://bit.ly/2Nw8Bvi $(14 / 04 / 2018)$

Callejo, J. (2010). El crítico estatuto de la persona adolescente en la observación empírica de la comunicación. Revista Estudios de Juventud, 88, 11-24. Recuperado de https://bit.ly/2x4sTTf (04/05/2018).

Cassany, D. (2008). Nativos e inmigrantes digitales en la escuela. Participación educativa: revista del Consejo Escolar del Estado; 9 (4): 57-75. Recuperado de https://bit.ly/2q13nF7 (25/04/2018). 
Castellón, L. y Jaramillo, O. (2002). Las múltiples dimensiones de la brecha digital. Reflexiones académicas, 13.

CCOO Enseñanza (2014). Envejecimiento del profesorado en España. Un estudio comparativo. Federación de Enseñanza de CCOO.

Clotfelter, C. T., Ladd, H. F., \& Vigdor, J. L. (2008). Scaling the digital divide: Home computer technology and student achievement. In Education Policy Colloquia Series, Harvard University, Cambridge, MA. Retrieved August (Vol. 19, p. 2009).

De Pablos, J. (1997). Tecnología de la educación: una reflexión sobre su identidad científica y académica. Revista Enseñanza, 15, 117-132. Recuperado de https://bit.ly/2oZuMw2 (11/05/2018).

Domínguez Caro, F. (2010). Competencia digital en la escuela: un recurso educativo decisivo para la transformación social, cultural y económica. Escolares entre pantallas. Revista http Grupo EDUCOM 1, 57-67. Recuperado de https://bit.ly/2x4J1ns (14/05/2018).

Domínguez Fernández, G., \& Jaén Martínez, A., \& Ceballos García, M. (2017). Educar la virtualidad. Pixel-Bit. Revista de Medios y Educación, (50), 187-199.

Fernández del Moral, J. F. (2012). La tercera y definitiva brecha digital. Identidad digital, 91, 6. Recuperado de https://bit.ly/2CVKmmf (19/04/2018).

Ferreiro, R. (2005). El reto de la educación del siglo XXI: la generación N. Apertura. Revista de innovación educativa, año $6, \mathrm{n}^{\mathrm{o}} 5,72-85$.

Ferrer, A. (2010). Millennials, la generación del siglo XXI. Nueva Revista de Política, Cultura y Arte, 130, 42-51.

Freire, J. (2007). ¿Quiénes son los nativos digitales?, y ¿por qué?. "Nómada”. Reflexiones personales e información sobre la sociedad y el conocimiento abiertos. Recuperado de https://bit.ly/1jR6Btp (07/072018).

Fryer, W. (2006). Beyond the digital native / immigrant dichotomy. Recuperado de https://bit.ly/2oZpikG (08/05/2018).

Fundación Telefónica (2015). La sociedad de la información en España 2014. Recuperado de https://bit.ly/2N29hZI (07/05/2018).

Gértrudix, F. y otros (2010). Una taxonomía del término "nativo digital”. Nuevas formas de relación y de comunicación. Gabinete de Comunicaciòn y Educaciòn, 1-17.

Granado, M. (2008). La otra educación audiovisual. Comunicar: Revista cientifica iberoamericana de comunicación y educación, (31), 563-570. Recuperado de 
https://bit.ly/2O8mWeh (27/04/2018).

Granado, M. (2011). Busco, no comparo, recorto y pego. El alumnado universitario y la información por Internet. Actas del II Congreso Internacional sobre uso y buenas prácticas con TIC. Universidad de Málaga.

Guaña- Moya, E. J. (2016). El analfabetismo digital en docentes limita la utilización de los EVEA. Revista Publicando, 3(8), 24-36. Recuperado de https://bit.ly/2CSJKOe (12/04/2018).

Hoffman, D. L., Novak, T. P. \& Schlosser, A. E. (2001). The evolution of the digital divide: Examining the relationship of race to Internet access and usage over time. En B. M. Compaine (Ed.), The digital divide (pp. 47-97). Cambridge, MA, EE.UU.: MIT Press.

Imedia Connection (2013). The 4 types of multi-screen users. Recuperado de https://bit.ly/2O9rAc5 (05/05/2018).

INE, Instituto Nacional de Estadística (2016). Encuesta sobre equipamiento y uso de tecnologías de información y comunicación en los hogares. Recuperado de https://bit.ly/1LJt9dw (18/05/2018).

Kennedy, G., Dalgarno, B., Bennett, S., Judd, T., Gray, K., \& Chang, R. (2008). Immigrants and natives: Investigating differences between staff and students' use of technology. Hello! Where are you in the landscape of educational technology.

Lluna, S. y Pedreira, J. (Coord.) (2017). Los nativos digitales no existen. Barcelona: Ed. Deusto.

Martín Labora, R. (2005). Las nuevas tecnologías en la educación. Auna Fundación: Cuadernos / Sociedad de la información 5.

Martínez, R., y Cussó, I. M. (2012). Cultures familiars, mitjans digitals i joves. Restriccions explícites $i$ implícites en la reproducció de l'avantatge generalitzat. Recuperado de https://bit.ly/2Q1JcTm (16/04/2018).

Milrad, M. \& others (2013). Seamless learning: An international perspective on next generation technology-enhanced learning. En Z. L. Berge \& L. Y. Muilenburg (Eds.), Handbook of mobile learning (pp. 95-108). New York: Routledge.

Ministerio de Educación, Cultura y Deporte (2017). Datos y cifras del curso 2017/18. Secretaría General técnica. Madrid: AEBOE.

Morales, J. M. R., Albero, C. T., y Molina, Ó. M. (2010). La brecha digital. Un análisis de las desigualdades tecnológicas en España. Recuperado de https://bit.ly/2MkBiXh (03/05/2018). 
Palfrey, J. \& Gasser, U. (2008). Born digital: understanding the first generation of digital natives. New York: Basic Books.

Yohyun Park (2016). How can we help kids protect themselves online? In World Economic Forum Annual Meeting. Recuperado de https://bit.ly/2CH2uQk (15/05/2018).

Pérez Tornero, J.M. y Tapis, V. (2012). Alfabetización mediática y nuevo humanismo. Barcelona: Universidad Autónoma de Barcelona.

Pinto Arboleda, M. C. (2014). La construcción de la referencia en torno al concepto de brecha digital en España. Signo y pensamiento, 33(64). Recuperado de https://bit.ly/1S5soI8 $(11 / 05 / 2018)$.

Prensky, M. (2001). Digital Natives Digital Immigrants. On the Horizon. Recuperado de https://bit.ly/IMBu0j (10/04/2018).

Prensky, M. (2001). Nativos digitales, inmigrantes digitales. On the Horizon. Recuperado de https://bit.ly/1oyxqpz (10/04/2018).

Prensky, M. (2010). Homo sapiens digital: de los inmigrantes y nativos digitales a la sabiduría digital. In Conectados en el ciberespacio (pp. 93-106). UNED.

Prensky, M. (2011). Enseñar a nativos digitales. Madrid: Ediciones SM.

Quicios, M., Ortega, I., y Trillo, M. (2015). Aprendizaje ubicuo de los nuevos aprendices y brecha digital formativa. Pixel-Bit. Revista de Medios y Educación, (46), 155-166. Recuperado de https://bit.ly/2CJB6Bp (06/05/2018).

Reig, D. y Vilches, L. F. (2013). Los jóvenes en la era de la hiperconectividad: tendencias, claves y miradas. Fundación Telefónica.

Robles, J., \& Molina, O. (2007). La Brecha digital: ¿una consecuencia más de las desigualdades sociales? Un análisis de caso para Andalucía. EMPIRIA. Revista de Metodología de las Ciencias Sociales, (13).

Rosabal, H. (2003). Inforicos Infopobres: la brecha digital. Centro de Medios de Información Alternativos de Québec.

Snyder, I. (2004). Alfabetismos digitales. Comunicación, innovación y educación en la era electrónica. Málaga: Aljibe.

Tarango, J. y Lau, J. (2009). Brecha más cognitiva que digital: papel de las habilidades informativas en países emergente. II Conferencia Internacional sobre Brecha Digital e Inclusión Social (Leganés, Madrid, del 28-30 de octubre de 2009). Recuperado de https://bit.ly/2x5wrnh (17/05/2028). 
Tezanos, J.F. (2001). La sociedad dividida. Estructuras de clases y desigualdades en la sociedad tecnológica. Madrid: Biblioteca Nueva.

Vega-Almeida, R. L. (2008). Brecha digital: un problema multidimensional de la sociedad emergente. Inclusão Social, 2(2). 